\title{
Ovulation, fertilization and early embryonic development in the bitch (Canis familiaris)
}

\author{
J. P. Renton ${ }^{1}$, J. S. Boyd ${ }^{2}$, P. D. Eckersall ${ }^{3}$, J. M. Ferguson ${ }^{4}$, \\ M. J. A. Harvey ${ }^{1}$, J. Mullaney ${ }^{1}$ and B. Perry ${ }^{5}$
}

Departments of ${ }^{1}$ Surgery/Reproduction, ${ }^{2}$ Anatomy and ${ }^{3}$ Biochemistry, University of Glasgow Veterinary School, Glasgow, UK; ${ }^{4}$ Wellcome Surgical Institute, University of Glasgow, Glasgow, UK; and ${ }^{5}$ Department of Pathological Biochemistry, Glasgow Royal Infirmary, Glasgow, UK

\begin{abstract}
Summary. Using circulating plasma hormone estimations, ovulation was monitored in bitches. The results obtained indicate that the timing of ovulation bears little relationship to alterations in sexual behaviour. The bitches were killed and reproductive tracts were removed at various intervals after ovulation and ova or embryos were recovered. The embryo stages were assessed visually and some were investigated histologically. Embryonic development, to early blastocyst stage, took place within the oviducts during the first 12 days after ovulation and there was a marked increase in size between the early and late blastocyst. A cuiture system using cells from the uterine tube supported the development of one 1-cell embryo to the morula stage.
\end{abstract}

Keywords: bitch; ovulation; fertilization; embryonic development

\section{Introduction}

Canine ova are very immature at ovulation (Van der Stricht, 1923); therefore, the timing of and the changes required for maturation and fertilization are of interest and importance for understanding reproduction in this species. The results presented in this report are on the relationship between the changes in behaviour and circulating plasma hormone concentrations during pro-oestrus and ovulation and of examinations of ova and embryos recovered by flushing uterine tubes or uteri at intervals after ovulation.

Reports in the literature describe certain aspects of the early embryonic development of the domestic bitch (Holst \& Phemister, 1971; Tsutsui, 1973, 1975). Holst \& Phemister assumed that ovulation occurred $24-48 \mathrm{~h}$ after the bitch first allowed mating and they determined the stage of embryonic development from that event. Later studies indicated that ovulations occur over several days after the beginning of standing oestrus (Wildt et al., 1978). Tsutsui $(1975,1989)$, on the other hand, determined the time of ovulation in the bitch by laparotomy and described the relationship between this event and subsequent gamete development. In the present study, ovulation was related to changes in circulating concentrations of plasma progesterone and luteinizing hormone.

\section{Materials and Methods}

Parous bitches were maintained in colony accommodation, fed a canned meat and meal diet and examined daily for signs of pro-oestrus. The first sign of pro-oestrous vaginal bleeding was recorded and monitoring was carried out as follows.

\section{Behavioural studies}

The bitch was teased daily with a stud dog and her sexual behaviour recorded. A proven stud dog was used to mate each bitch daily over the period when she would accept the male. 


\section{Endocrinology}

From the start of pro-oestrous bleeding, blood samples were collected by cephalic venepuncture into heparinized Monovet tubes (Sarstedt, Leicester, UK). The samples were centrifuged at $1000 \mathrm{~g}$ for $10 \mathrm{~min}$ and the plasma was separated and stored at $-20^{\circ} \mathrm{C}$.

Luteinizing hormone. Plasma LH was measured by the double antibody radioimmunoassay method of Boyns et al. (1972) with modifications as follows. Iodination: purified ovine LH (LER 1374A, kindly donated by Dr L. Reichert, Albany Medical College) was labelled with $37 \mathrm{MBq}$ of ${ }^{125}$ I (Amersham, UK). A freshly prepared solution of chloramine T ( $10 \mathrm{mg}$ in $10 \mathrm{ml} 0.05 \mathrm{M}$ phosphate buffer $\mathrm{pH} \mathrm{7.4)} \mathrm{was} \mathrm{added} \mathrm{and} \mathrm{left} \mathrm{for} 30 \mathrm{~s}$. The reaction was stopped by the addition of a freshly prepared solution of sodium metabisulphite $(20 \mathrm{mg}$ in $10 \mathrm{ml} 0.05 \mathrm{M}$ phosphate buffer) and the mixture was then applied to a G-150 sephadex column $(100 \times 1.6 \mathrm{~cm})$ and eluted with elution buffer $(0.05 \mathrm{M}$ phosphate buffer containing $0.9 \%(\mathrm{w} / \mathrm{v})$ sodium chloride, $0.5 \%(\mathrm{w} / \mathrm{v})$ bovine serum albumin (BSA) and $0.1 \%(\mathrm{w} / \mathrm{v})$ sodium azide). The first antibody used, rabbit antirat LH serum (CSU120) at a dilution of 1:20000 in assay buffer (0.05M phosphate buffer containing $0.25 \%(\mathrm{w} / \mathrm{v}) \mathrm{BSA}, 0.1 \%(\mathrm{w} / \mathrm{v})$ sodium azide and $0.05 \%(\mathrm{v} / \mathrm{v})$ triton $\mathrm{X}-100)$ was supplied by G. D. Niswender who has successfully used this antibody for canine LH assays (personal communication). The standard used was purified pituitary canine LH (LER 1685-1; Dr L. Reichert) to which it was found necessary to add LH-free serum (prepubertal bitch blood). Recovery studies revealed that the addition of $12.5 \mathrm{ng}$ of canine $\mathrm{LH} / \mathrm{ml}$ gave a recovery value of $81 \%$ and the addition of $6.25 \mathrm{ng}$ of canine $\mathrm{LH} / \mathrm{ml}$ gave a recovery of $68 \%$, this being carried out once. The second antibody used was Dynospheres donkey antirabbit (McConway et al., 1986). The range of the assay was up to a value of $50 \mathrm{ng} / \mathrm{ml}$ and the sensitivity was 0.66 (mean $0.65 \pm 0.68$ ) assessed over 16 assays. The interassay coefficient of variance, calculated from 19 assays, was $20 \%$ at $5 \mathrm{ng} \mathrm{LH} / \mathrm{ml}$ and $35 \%$ at $10 \mathrm{ng} \mathrm{LH} / \mathrm{ml}$. The intraassay coefficient of variance, derived by assaying the same quality control samples 6 times, had a standard deviation of 0.76 at $5 \mathrm{ng} \mathrm{LH} / \mathrm{ml}$ and a standard deviation of 4.7 at $20 \mathrm{ng} \mathrm{LH} / \mathrm{ml}$.

Plasma progesterone. Concentrations were assayed using an ELISA kit (Ovucheck Bovine Plasma, Cambridge Veterinary Sciences Ltd, Ely, UK), according to the method of Eckersall \& Harvey (1987). The intended working range of the assay was $1.5-32 \mathrm{nmol} / 1$. The interassay variation was calculated by including one high standard $(8 \mathrm{nmol} / \mathrm{l})$ and one low standard $(2.5 \mathrm{nmol} / \mathrm{l})$ for each assay. From these results, the coefficients of variation were 14.05 and $16.4 \%$, respectively. The intra-assay variation was assessed by including the same high and low samples 10 times in one assay, and from these results the coefficients of variation were $13 \cdot 1$ and $10 \cdot 3 \%$ for these samples.

\section{Embryo collection}

At intervals after ovulation, 10 bitches were killed and their reproductive tracts recovered for examination.

Uterine tube flushing. Each uterine tube was flushed separately. After identification of the infundibulum, a cannula of 3-5 F gauge diameter (depending on the individual uterine tube size) was inserted and tied firmly in place with silk. Prior to flushing, the uterine horn on the cannulated side was cut immediately distal to the uterotubal junction. The uterine tube was flushed with 4-5 ml Hepes-buffered Ham's F10 medium (Flow Laboratories, Rickmansworth, UK) with $10 \%$ fetal calf serum (Flow Laboratories) and the flushing collected from the incised end of the uterine tube into an embryo dish. If contaminated with blood, the flushing was passed through a $70 \mu \mathrm{m}$ embryo filter using the same flushing solution.

Uterine flushing. Each uterine horn was flushed separately. A 21-gauge needle was introduced into the horn immediately proximal to the uterine bifurcation. The uterine horn was severed distal to the uterotubal junction. The contralateral horn was clamped with forceps and 5-10 $\mathrm{ml}$ of flushing medium, as used for uterine tube flushing, was injected through the needle into the ipsilateral horn and collected from the cut end of the horn into a collecting dish. The contralateral uterine horn was then flushed in a similar manner.

\section{Embryo studies}

The flushings were examined for the presence of ova and embryos using a stereomicroscope at $\times 12$ magnification. Assessment of embryos was carried out using an invert microscope at $\times 320$ (Wilovert, Leitz). After assessment, each embryo was transferred into fresh Ham's F10 $+20 \%$ fetal calf serum and subsequently allocated to different studies.

Sectioning. Embryos were fixed in $2.5 \%$ gluteraldehyde, post-fixed in $1 \%$ osmium tetroxide and embedded in Araldite. Serial $1 \mu \mathrm{m}$ sections were cut and stained with toluidine blue. A representative sample of embryos from each bitch was processed.

Culturing. After removal of the eggs, the flushings were centrifuged at $60 \mathrm{~g}$ for $10 \mathrm{~min}$ and, after removal of the supernatant, the uterine tube cell material was resuspended in M199 (Flow laboratories) $+20 \%$ fetal calf serum and placed in a 12-well culturing plate (Nunc, Kamstrup, Denmark). In this study one egg (from bitch no. 1) was placed in the same culture medium. Incubation was carried out at $37^{\circ} \mathrm{C}$ in a humidified atmosphere of $95 \%$ air supplemented with $5 \% \mathrm{CO}_{2}$ and examined and photographed daily under an invert microscope. At the end of the culture period, 
cells were counted using a sandwich technique. A drop of a mixture of 9:1 Paraffin Wax:Vaseline was placed at each corner of an alcohol-cleaned $22 \mathrm{~mm}$ coverslip. The egg, in a drop of medium, was placed on a similarly cleaned slide, and the coverslip was placed over the drop and gently pressed down until the egg was slightly compressed. This was carried out using a dissecting microscope at $\times 50$ magnification. The egg was fixed overnight in 3:1 methanol:acetic acid. The slide was subsequently stained in $1 \%$ aceto-orcein for $5 \mathrm{~min}$, then decolorized in $45 \%$ acetic acid, dehydrated and cleared prior to permanent mounting. Nuclei were counted under oil at $\times 540$.

\section{Results}

Concannon et al. (1989) reported little variation in the 2-day interval between the LH surge and ovulation in the bitch. This criterion was applied in these studies.

\section{Plasma progesterone}

Concannon \& Lein (1989) reported that circulating plasma progesterone concentrations rise slowly from $<0.5 \mathrm{ng} / \mathrm{ml}$ at the beginning of pro-oestrus to $\sim 1 \mathrm{ng} / \mathrm{ml}$ at the start of the $\mathrm{LH}$ surge, increasing to $2-4 \mathrm{ng} / \mathrm{ml}$ during the LH surge. Based on these findings and our experience in $>20$ bitches, it was decided to recognize the day on which the circulating plasma progesterone was $\sim 3 \mathrm{ng} / \mathrm{ml}$, and continued to rise, as being the pre-ovulatory phase and to assume that ovulation occurred 2 days later. When there was a discrepancy between results, the LH results were used.

\section{Behaviour}

First acceptance of the male by the bitches ranged from 3 days before to 3 days after ovulation (Table 1). The interval between the commencement of vaginal bleeding and first acceptance of the male ranged between 6 and 22 days, which is similar to our findings in clinical cases referred for fertility assessment (J. P. Renton \& M. J. A. Harvey, unpublished). Only 5 of 10 bitches first stood on or within 1 day of the actual or hypothesized LH surge (the latter based on the progesterone results if $\mathrm{LH}$ was not assayed); 2 of 10 first stood 2 days after that; and 3 of 10 stood for the first time only after ovulation.

\section{Embryo collection}

Of the many technical obstacles to be overcome in this study, the first was the location and cannulation of the uterine tube, to expedite flushing of ova and/or embryos. In the bitch each uterine tube is, on average, $4-7 \mathrm{~cm}$ long and $1-3 \mathrm{~mm}$ in diameter. The infundibulum is funnel shaped and is near the edge of the opening into the ovarian bursa. The lumen of the uterine tube then narrows into a minute opening, the abdominal ostium, which is the origin of the tubal portion of the uterine tube (Evans \& Christiansen, 1979).

From the abdominal ostium, the uterine tube runs caudolaterally before bending sharply cranially. This deviation causes obstruction to placement of a cannula and so in our studies a cannula of only 15-20 mm long was introduced, using a dissecting microscope at $\times 70$ magnification to view the infundibulum.

\section{Embryo stages}

The results presented in Table 1 cover a wide range in the time of flushing after ovulation. This is reflected in the wide spectrum of embryo stages recovered. Histological studies of two of the 1cell eggs from bitch no. 2 suggested that these were probably fertilized, in that one egg had sperm embedded in the cumulus layer (Fig. 1a) and another possessed two structures which were interpreted as pronuclei (Fig. 1b). The one egg cultured from bitch no. 1 (Fig. 2) cleaved, thus confirming that it was a fertilized 1-cell egg at removal. The earliest post-ovulation stages from 


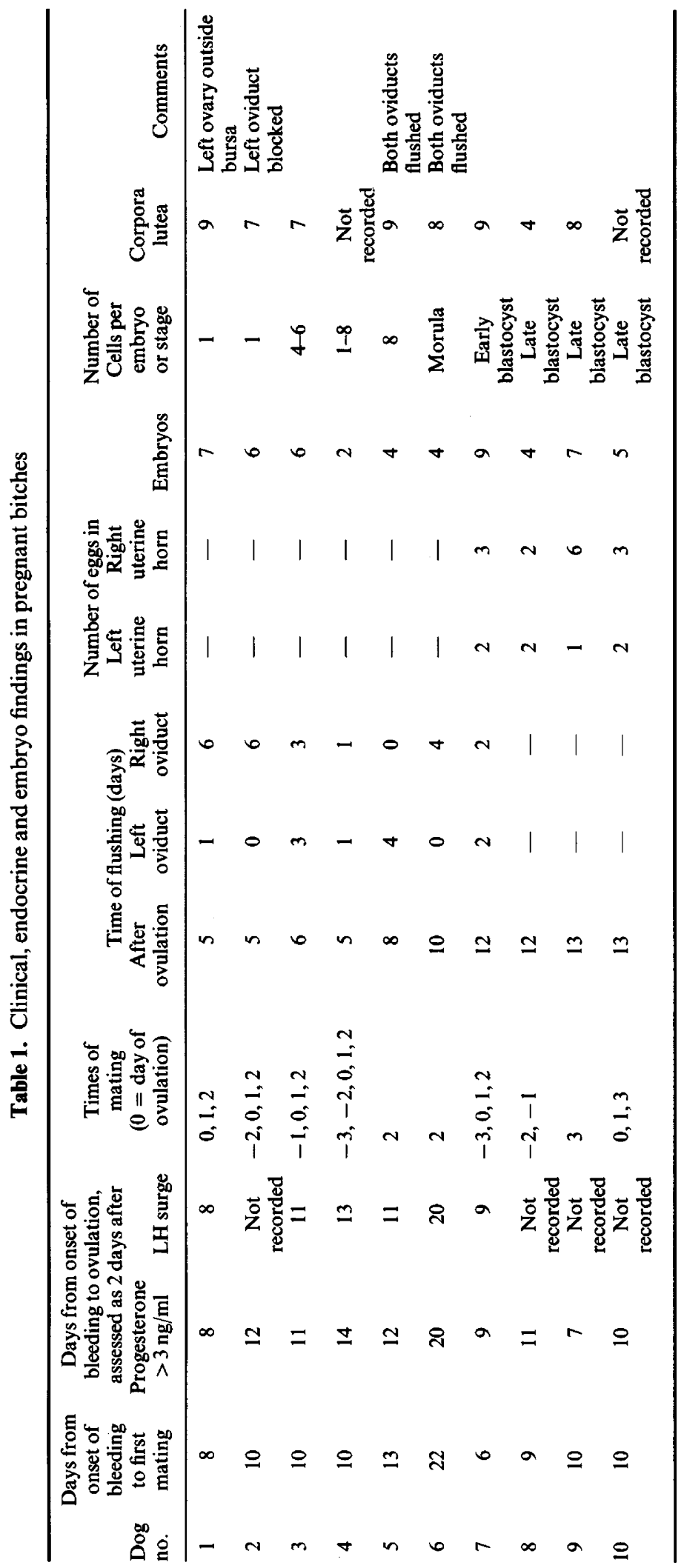




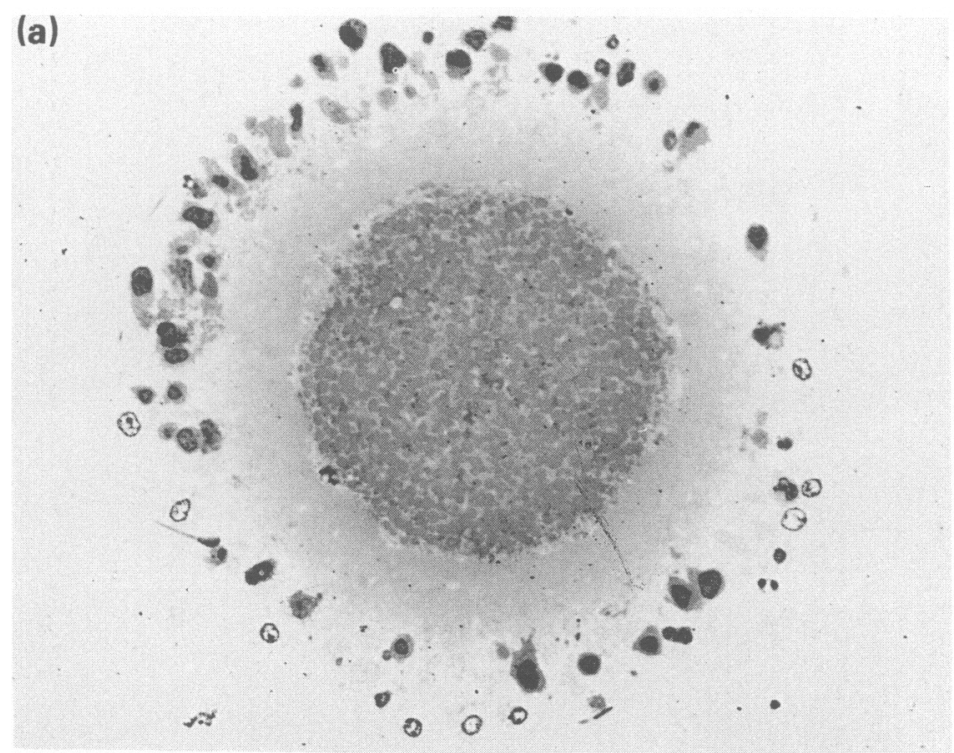

(b)

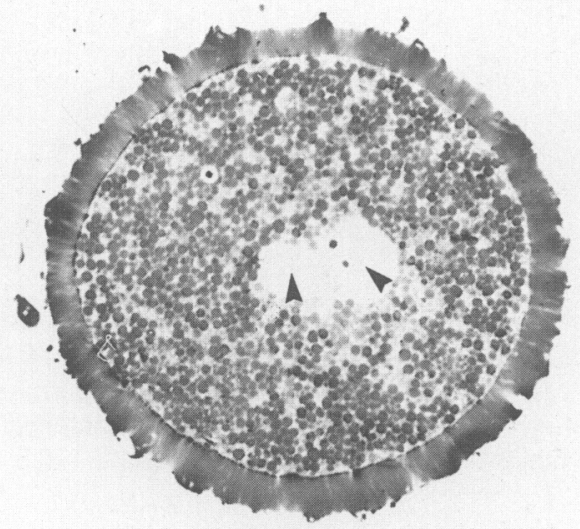

Fig. 1. 1-cell eggs from oviducts of bitch no. 2, 5 days after ovulation. Araldite sections $(1 \mu \mathrm{m})$ ( $\times 200$ ): (a) spermatozoa embedded in cumulus layer and (b) 2 pronuclei present (arrows) indicating fertilization.

which cleaved eggs were obtained were Day 5 (8-cell stage, bitch no. 4) and Day 6 (4- and 6-cells, bitch no. 3). Morulae were recovered from bitch no. 6 at Day 10. These and all of the embryos from bitches flushed at earlier stages were recovered exclusively from the uterine tube. The embryos recovered from the uterine tube and uterus from bitch no. 7, at Day 12, were all at the early blastocyst stage. Later-stage blastocysts were recovered exclusively from the uterus. Comparison between the early and late blastocysts (Fig. 3a, b) showed that there was an obvious thinning of the zona pellucida at the late blastocyst stage as well as an increase in size. All the blastocysts collected 

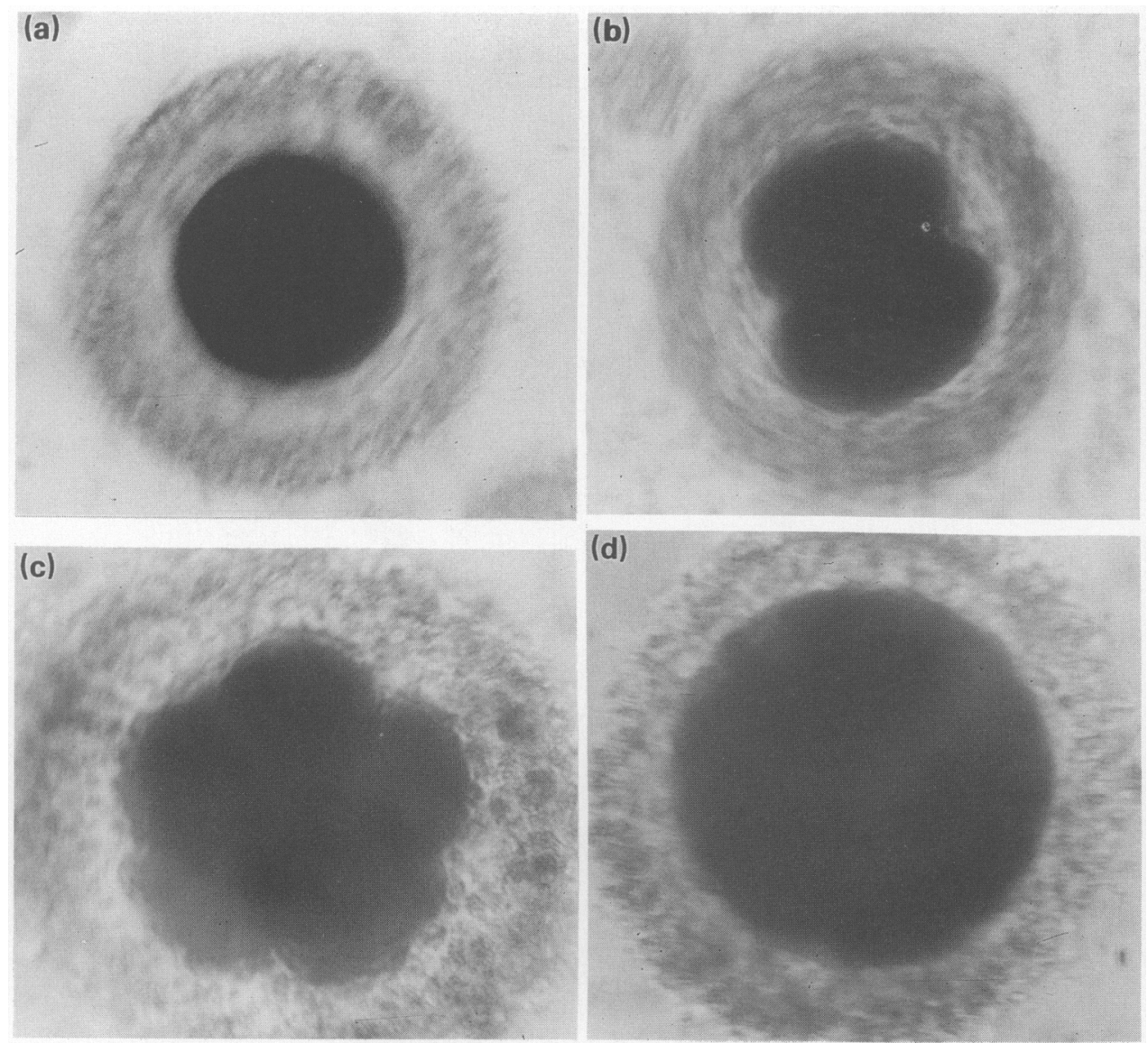

Fig. 2. Egg collected from oviduct of mated bitch (no. 1), 5 days after ovulation, cultured as described in text (times refer to hours after placing in culture): (a) $0 \mathrm{~h}, 1$-cell stage; fuzziness is caused by rotation of the egg due to the motility of attached spermatozoa $(\times 220)$; (b) $+24 \mathrm{~h}$, egg has cleaved to 2-cell stage. Egg still rotating because of attached spermatozoa which were still active $(\times 220)$; (c) $+96 \mathrm{~h}$, 8-cell stage (phase $\times 360)$; $(\mathrm{d})+120 \mathrm{~h}$, morula (phase $\times 360$ ).

underwent a high degree of trophoblast contraction almost immediately after being placed in the flushing medium (Fig. 4a). This structural change was almost totally reversed when the blastocysts were subsequently placed in the same medium diluted with an equal volume of distilled water (Fig. 4b).

\section{Embryo culture}

In an egg from bitch no. 1 obtained 5 days after ovulation (Fig. 2a) and subsequently cultured for $120 \mathrm{~h}$ (Fig. $2 \mathrm{~d}$ ), the first cleavage took place $\sim 23 \mathrm{~h}$ after collection, i.e. $\sim 6$ days after ovulation. The subsequent divisions had occurred by 48,96 and $120 \mathrm{~h}$ (Fig. $2 \mathrm{~b}-\mathrm{d}$ ), when the embryo was killed to count the nuclei. Bitch eggs are easily ruptured during this technique and there was partial loss of material during the processing of this egg. In spite of the leakage, 5 stained nuclei were identified, confirming the microscopic appearance of a morula (Fig. 2d) in that at least 3 cleavage divisions must have occurred. 


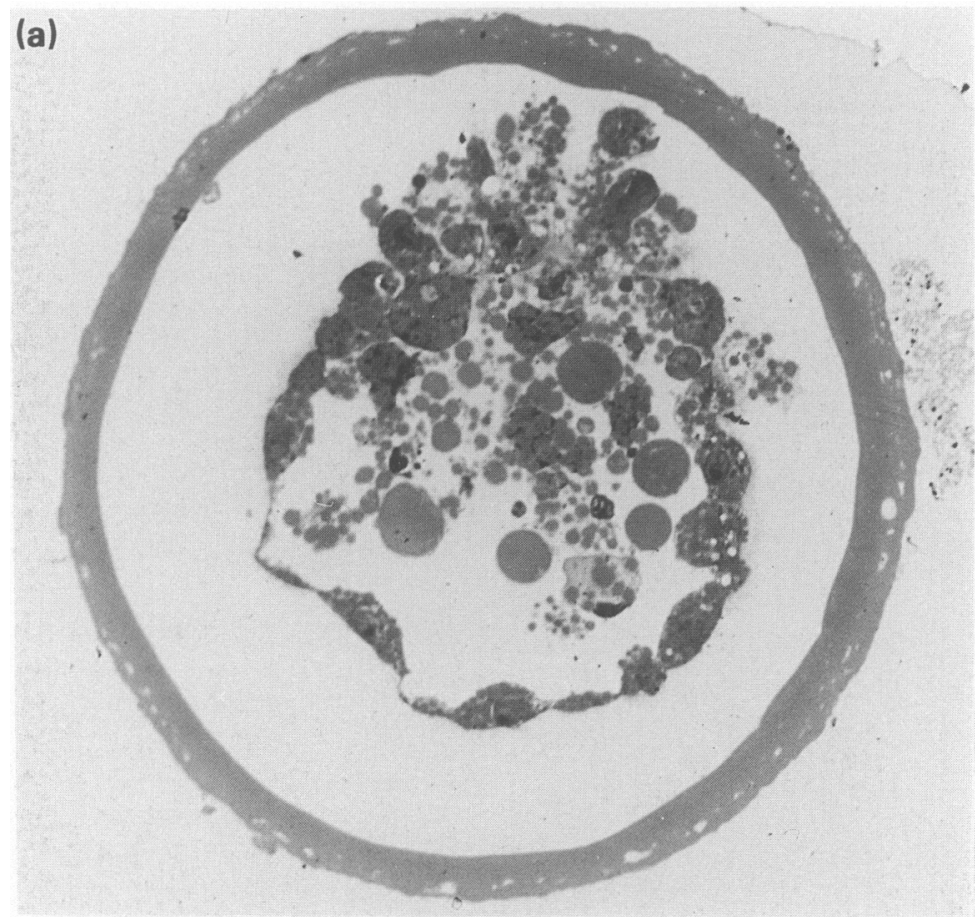

(b)

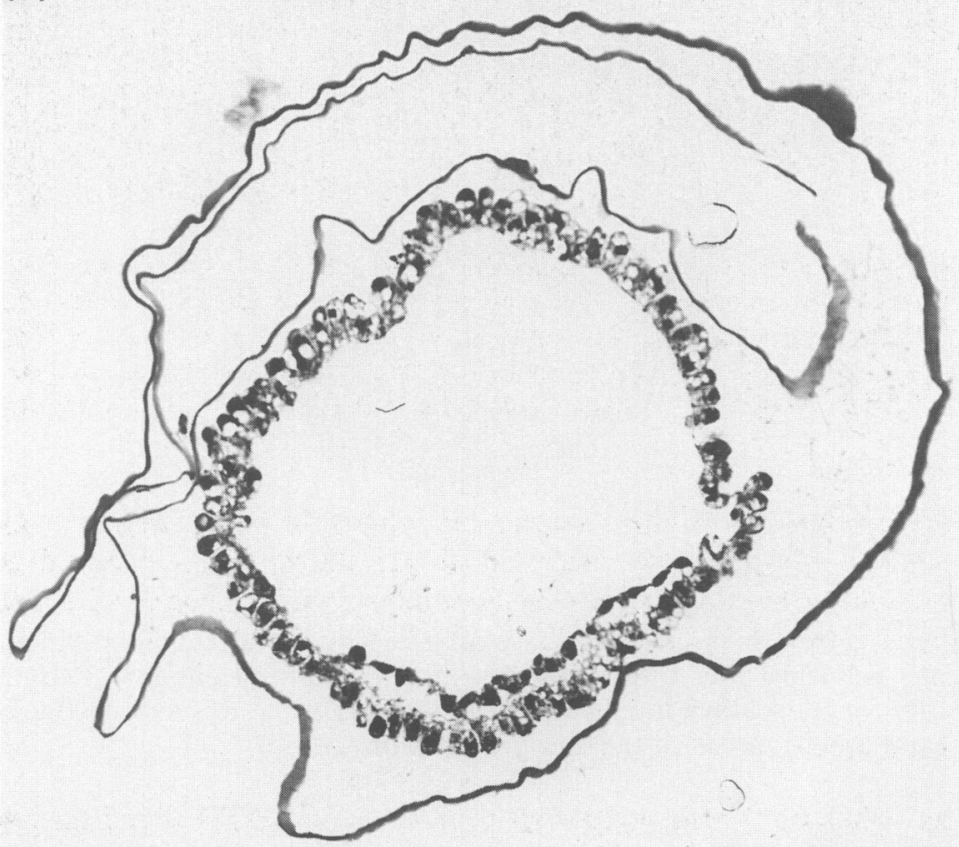

Fig. 3. Araldite sections $(1 \mu \mathrm{m})$ of (a) early blastocyst from bitch no. 7 (12 days after ovulation) $350 \mu \mathrm{m}$ diameter $(\times 200)$ and (b) late blastocyst from bitch no. 9 (13 days after ovulation) $1000 \mu \mathrm{m}$ diameter $(\times 100)$. 


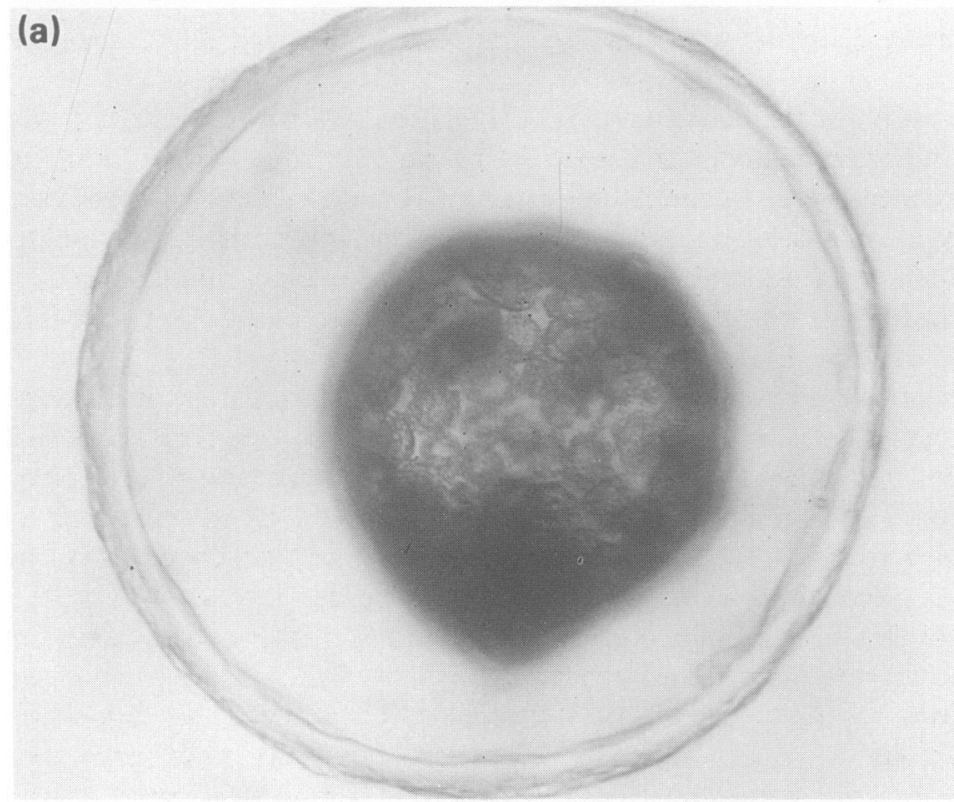

(b)

Fig. 4. Blastocysts from bitch no. 7, 12 days after ovulation; (a) trophoblast shrunken away from the zona pellucida after short storage in tissue culture medium $(\times 360)$ and $(b)$ same blastocyst after $5 \mathrm{~min}$ in culture in 1:1 Ham's F10:distilled water; this returned the blastocyst to almost the same appearance as at the time of collection $(\times 360)$.

\section{Discussion}

The clinical investigations demonstrated great variability, in the interval between the commencement of vaginal bleeding and first acceptance of the male (Table 1). It has been suggested that the initial changes in behaviour from merely flirting with the male to allowing intromission can be 
related to ovulation (Christiansen, 1984), but our studies indicated that in most instances this was not so.

The main criteria for the determination of ovulation in the bitches studied were related to the LH surge and the pre-ovulatory rise in circulating plasma progesterone. In all 6 of the bitches in which both were measured, the circulating plasma LH concentrations agreed closely with the estimated time of ovulation based on the progesterone concentration; the two estimates agreed exactly or were different by no more than 1 day. The duration of ovulation has been variably recorded as occurring over only a few hours (Concannon et al., 1989), over 12-72 h (Graf, 1978) and even over several days (Wildt et al., 1978).

The number of corpora lutea identified on the ovary seldom agreed with the number of ova or embryos collected (Table 1). This has been recorded in other species where flushing of eggs or embryos has been performed (Hamlet, 1983), and it may be that, at ovulation, some of the eggs do not enter the uterine tube. Fimbria fringing the edge of the infundibulum have a ciliary function and waft the ova into the abdominal ostium. From ovulation until envelopment by the infundibulum, ova are within the bursa, where some of them may be lost. It was not possible to cannulate one uterine tube in bitch no. 2 and in two others (nos 5 and 6) neither ova nor embryos were obtained from one of the uterine tubes. The bitches used had been used in breeding previously and in 2 , Caesarian sections had been carried out at a previous parturition. The failure to cannulate or to obtain embryos could have been due to uterine tube blockage caused either by a Caesarian section or by ascending infection from a post-partum metritis. There was no record of previous Caesarian sections or metritis in these 2 bitches, but the latter possibility cannot be excluded. Evidence from cattle has shown that narrowed uterine tubes can be cannulated, but only fluid, and not eggs, pass (Kelly, 1981); this could be an explanation in these cases.

The ovum and early embryo of the bitch is surrounded by a thick zona pellucida and is packed with lipid which hampers observation of the cytoplasmic contents (Figs 1 and 2). The ovum has been reported to take $2-5$ days after ovulation to reach a fertilizable state (Christiansen, 1984). In the present study, one 8-cell egg was collected 5 days after ovulation from bitch no. 4 . Three cleavage divisions are required to reach this stage and would have been expected to occur over $\sim 3$ days (Tsutsui, 1975), suggesting that fertilization had taken place $\sim 2$ days after ovulation. In contrast, the fertilized 1-cell egg recovered from bitch no. 1, which divided in culture, was also collected 5 days after ovulation. Findings from the other bitches confirmed the theory that individual variation in the time of fertilization occurs, in that bitches nos 4 and 5 had 8-cell eggs at Days 5 and 8 after ovulation, respectively. Such variations are also reported by Tsutsui (1975), who based his timing of ovulation on laparoscopic observation. Although Holst \& Phemister (1971) reported that all the follicles in the bitch rupture at the same time, other studies have found that ova are ovulated over at least $24 \mathrm{~h}$ (Graf, 1978; J. S. Boyd, unpublished). The findings of Graf and Boyd indicate that some ova appear to remain quiescent in the uterine tube for differing periods prior to fertilization. In agreement with Tsutsui (1975), the present study found that all the cleaved eggs from any one bitch were at approximately the same stage of development, but that the stage varied markedly between bitches. The one exception was bitch no. 4, in which both 1 - and 8-cell eggs were found. No spermatozoa were found embedded in either the zona pellucida or the cumulus layer in the 1-cell egg and, taken together with the fact that this egg was retarded by 3 divisions, indicated that it was unfertilized. This was the only l-cell egg found at this period after ovulation, agreeing with Tsutsui (1989) that a high rate of fertilization occurs in the bitch.

Histological examination of the early developing embryos indicated that, at the late blastocyst stage (Fig. 3b), the structure which surrounds it is markedly thinner than the zona pellucida which surrounds the early embryo (Fig. 3a). It is reported that in mares the zona pellucida is shed around Day 8 following its replacement by an acellular capsule (Flood et al., 1982) and studies are continuing to determine whether such a process occurs in bitches.

The successful culture of an egg, which was fertilized either in vivo or possibly after being placed in culture medium with spermatozoa matured in vitro, is, to our knowledge the first to be reported 
in bitches. Studies in other domestic species have reported a block to the further development of the fertilized egg in tissue culture medium alone (Wright \& Bondioli, 1981). This block apparently occurs at different embryonic stages depending on the species. However, recently it has been reported that in sheep and cattle this block can be overcome by culturing eggs on established monolayers of uterine tube cells (Gandolfi \& Moor, 1987; Eyestone \& First, 1989). In the present study, uterine tube cells were present in the uterine tube flushings, but were not established monolayers. This might suggest that the egg would have developed in cell-free medium, as in certain strains of mice. Indeed, Tervit et al. (1973) in sheep, and Pope et al. (1990) in cats, have reported successful culture of eggs using simple media. Obviously, further studies are required in bitches to determine the necessary cultural requirements for future in-vitro fertilization experiments.

In bitch no. 6, morulae were recovered from the uterine tubes 10 days after ovulation, whereas in bitch no. 7, early blastocysts were apparently collected from the uterine tube and uterus 12 days after ovulation. As a small portion of the proximal extremity of the horn of the uterus remains when the uterine tube is flushed, it is possible that the blastocysts in this particular bitch were actually lying in the uterine horn and not retained within the uterine tube. However, Tsutsui (1975) recovered morulae from both uterine tube and uterus 8 or 9 days after ovulation. Thus, the embryo of the bitch appears to remain in the uterine tube for $\sim 9-10$ days after ovulation, entering the uterus either in the late morula or early blastocyst stage. In bitch no. 7, the blastocysts flushed on Day 12 after ovulation were only $350 \mu \mathrm{m}$ in diameter, but in bitches nos 9 and 10 flushed on Day 13 after ovulation, the blastocysts recovered were $\sim 1000 \mu \mathrm{m}$ in diameter. This dramatic increase over $24 \mathrm{~h}$ may reflect rapid growth or be a further example of the individual variation in the interval from ovulation to fertilization. If the latter is a feature of bitches, it is interesting that the gestation period, counted from the day of ovulation, is remarkably constant (Concannon et al., 1983) and suggests that the possible individual variation in the interval from ovulation to fertilization is eliminated to a large extent during gestation.

Ham's F10 medium is used in our laboratory for holding both canine and equine blastocysts and has an osmolarity of $\sim 270-310 \mathrm{mosmol} / 1$. When canine blastocysts were added to the medium, they decreased in volume and the trophoblast became detached from the zona pellucida (Fig. 4a). A similar effect had been noted when similar-stage embryos were placed in phosphate-buffered saline. Partial recovery was achieved by placing the embryos in diluted medium (Fig. 4b), suggesting that the osmolarity in the canine embryo is lower than that of the flushing media. This shrinking process does not occur in equine blastocysts when handled similarly and suggests that there must be markedly differing uterine environments in these two species.

The work was carried out under grant no. 19679/1.5 from Wellcome Trust. We also thank Pfizer Central Research for financial support, M.M. Waterston for technical assistance and A. May for photographic help.

\section{References}

Boyns, A.R., Jones, G.E., Bell, E.T., Christie, D.W. \& Parkes, M.F. (1972) Development of a radioimmunoassay for canine luteinizing hormone. $J$. Endocr. 55, 279-291.

Christiansen, I.B. (1984) Reproduction in the Dog and Cat, pp. 41-54. Bailliere Tindall, London.

Concannon, P.W. \& Lein, D.H. (1989) Hormonal and clinical correlates of ovarian cycles, ovulation, pseudo-pregnancy and pregnancy in dogs. In Current Veterinary Therapy, Small Animal Practice, vol. X, pp. 1269-1282. Ed. R. W. Kirk. W.B. Saunders, Philadelphia.

Concannon, P.W., Whaley, S., Lein, D. \& Wissler, R. (1983) Canine gestation length: variation related to time of mating and fertile life of sperm. Am. J. Vet. Res. 44, 1819-1821.

Concannon, P.W., McCann, J.P. \& Temple, M. (1989) Biology and endocrinology of ovulation, pregnancy and parturition in the dog. J. Reprod. Fert., Suppl.39, 3-25.

Doak, R.L., Hall, A. \& Dale, H.E. (1967) Longevity of spermatozoa in the reproductive tract of the bitch. $J$. Reprod. Fert. 13, 51-58.

Eckersall, P.D. \& Harvey, M.J.A. (1987) The use of a bovine plasma progesterone ELISA kit to measure progesterone in equine, bovine and canine plasma. Vet. Rec. 120, 5-8.

Evans, H.E. \& Christiansen, G.C. (1979) Miller's Anatomy of the Dog, 2nd edn. W.B. Saunders, Philadelphia. 
Eyestone, W.H. \& First, N.L. (1989) Co-culture of early cattle embryos to the blastocyst stage with oviductal tissue or in conditioned medium. J. Reprod. Fert. 85, 715-720.

Flood, P.F., Betteridge, K.J. \& Diocee, M.S. (1982) Transmission electron microscopy of horse embryos 3-16 days after ovulation. J. Reprod. Fert., Suppl. 32, 319-327.

Gandolfi, F. \& Moor, R.M. (1987) Stimulation of early development in sheep by co-culture with oviduct epithelial cells. J. Reprod. Fert. 81, 23-28.

Gilbert, R.O. \& Boser, W.T.K. (1987) Clinical reproductive endocrinology of the dog and cat. In Small Animal Endocrinology, pp. 341-371. Ed. F.H. Drazner. Churchill, Livingstone, New York.

Graf, K.-J. (1978) Serum oestrogen, progesterone and prolactin concentrations in cyclic, pregnant and lactating beagle dogs. J. Reprod. Fert. 52, 9-14.

Hamlet, E.J. (1983) Cytogenetic abnormalities in early embryos of the sheep and pig. Ph.D. thesis, University of Glasgow.

Holst, P.A. \& Phemister, R.D. (1971) The prenatal development of the dog: pre-implantation events. Biol. Reprod. 5, 194-206.

Kelly, E.F. (1981) A study of some aspects of the oviducts in normal and infertile cattle. $\mathrm{Ph} . \mathrm{D}$. thesis, University of Glasgow.

McConway, M.G., Bell, M.A. \& Chapman, R.S. (1986) Automation of solid phase radioimmunoassays for prolactin, LH and follicle stimulating using Dynospheres and the Kemtek 3300. Ann. clin. Biochem. 26, 292-293.
Pope, C.E., Gelwicks, E.J., Turner, J.L., Keller, G.L. \& Dresser, B.L. (1990) In vitro fertlization in the domestic cat: effect of medium on development during a four-day culture period in vitro. Theriogenology 33, 299.

Tervit, H.R., Whittingham, D.G. \& Rowson, L.E.A. (1973) Successful culture in vitro of sheep and cattle ova. J. Reprod. Fert. 30, 493-497.

Tsutsui, T. (1973) Studies on the physiology of reproduction in the dog. II. Observation on the time of ovulation and fertilisation in dogs. Jap. J. Anim. Reprod. 18, 137-142.

Tsutsui, T. (1975) Studies on reproduction in the dog. V. On cleavage and transport of fertilised ova in the oviduct. Jap. J. Anim. Reprod. 21, 70-75.

Tsutsui, T. (1989) Gamete physiology and timing of ovulation and fertilisation in dogs. J. Reprod. Fert., Suppl. 39, 269-275.

Van der Stricht, O. (1923) Etudes comparées des ovules des mammifières aux differente periodes de l'ovogenese d'apres les travaux du Laboratoire d'Histologie et d'Embryologie de l'Universite de Gand. Arch. Biol. 33, 231-300.

Wildt, D.E., Chakraborty, P.K., Panko, W.B. \& Seager, S.W.J. (1978) Relationship of reproductive behaviour, serum luteinising hormone and time of ovulation in the bitch. Biol. Reprod. 18, 561-570.

Wright, Jr, R.W. \& Bondioli, K.R. (1981) Aspects of in vitro fertilisation and embryo culture in domestic animals. J. Anim. Sci. 53, 702-729.

Received 29 November 1990 